\title{
Transglutaminase 2 facilitates the distant hematogenous metastasis of breast cancer by modulating interleukin- 6 in cancer cells
}

Keunhee Oh ${ }^{1,2}$, Eunyoung Ko ${ }^{3,4}$, Hee Sung Kim ${ }^{5}$, Ae Kyung Park ${ }^{6}$, Hyeong-Gon Moon ${ }^{3}$, Dong-Young Noh ${ }^{3}$ and Dong-Sup Lee ${ }^{1,2^{*}}$

\begin{abstract}
Introduction: Inflammation has been implicated in cancer aggressiveness. As transglutaminase 2 (TG2), which has been associated with inflammatory signaling, has been suggested to play a role in tumor behavior, we propose that TG2 may be an important linker inducing interleukin (IL)-6-mediated cancer-cell aggressiveness, including distant hematogenous metastasis.

Methods: To investigate the role for TG2 and IL-6, TG2-knocked-down and IL-6-knocked-down cancer cells were generated by using shRNA. Human breast cancer cell xenograft model in highly immunocompromised mice and human advanced breast cancer primary tumor tissue microarrays were used in this study.

Results: IL-6 production in human breast cancer cells was dependent on their TG2 expression level. In vitro tumorsphere formation was dependent on TG2 and downstream IL-6 production from cancer cells. Primary tumor growth in the mammary fat pads and distant hematogenous metastasis into the lung was also dependent on TG2 and downstream IL-6 expression levels. The effect of TG2 expression on human breast cancer distant metastasis was investigated by analyzing a tissue microarray of primary tumors from 412 patients with their clinical data after 7 years. TG2 expression in primary tumor tissue was inversely correlated with recurrence-free survival $(P=0.019)$ and distant metastasis-free survival (DMFS) $(P=0.006)$ in patients with advanced breast cancer. Furthermore, by using public datasets that included a total of 684 breast cancer patients, we found that the combined high expression of TG2 and IL-6 was associated with shorter DMFS, compared with the high expression of IL-6 only ( $P=0.013)$.

Conclusions: We provide evidence that TG2 is an important link in IL-6-mediated tumor aggressiveness, and that TG2 could be an important mediator of distant metastasis, both in a xenograft animal model and in patients with advanced breast cancer.
\end{abstract}

\section{Introduction}

Immune/inflammatory responses have largely been considered a key protective mechanism of hosts against growing tumor cells [1]. However, inflammation is now also recognized to be important in the pathogenesis of many types of malignancies [2]. Persistent Helicobacter pylori infection is associated with gastric cancer [3]. Viral infections lead to chronic inflammation and are responsible for the majority of hepatocellular

\footnotetext{
* Correspondence: dlee5522@snu.ac.kr

1 Laboratory of Immunology, Interdisciplinary Program of Tumor Biology, Cancer Research Institute, Seoul National University College of Medicine, 28 Yongon-dong Chongno-gu, Seoul 110-799, Korea

Full list of author information is available at the end of the article
}

carcinomas [4]. Obesity also promotes chronic inflammation and results in a substantial increase in cancer risk in the liver [5] and pancreas [6].

Inflammation thus triggered by infection, obesity, or the tumor itself recruits inflammatory cells to the tumor-stroma interface, and these cells, together with the tumor cells, generate a microenvironment capable of driving tumor progression [7]. The concerted action of inflammatory cytokines, together with oxidative stress and hypoxia in the tumor environment converge to activate nuclear factor (NF)- $\kappa \mathrm{B}$ in cancer cells [8]. NF- $\kappa \mathrm{B}$ signaling has been implicated in several cancer cell

\section{C) Biomed Central}


behaviors, including initiation, promotion, survival, malignant conversion, invasion, and metastasis [9].

Interleukin (IL)-6 is an important downstream effector of NF- $\kappa$ B. High serum IL- 6 levels correlate with poor disease outcome and reduced clinical prognosis in patients with breast, lung, and liver cancer [10,11] and with cancer formation in a murine colitis-associated colon cancer model [12]. IL-6, produced from bone marrow-derived cells, promotes growth of tumor-initiating cells during early tumorigenesis and protects these cells from apoptosis [12]. Furthermore, IL-6 produced in epithelial cancer cells themselves plays an important role in tumor growth and metastasis, in an autocrine and/or paracrine manner. IL-6 signaling pathways in epithelial cancer cells have also been linked to in vivo aggressiveness by affecting epithelial-to-mesenchymal conversion $[13,14]$ or conferring the cancer stem cell-like properties of these cells [15]. The molecular links leading to IL-6 production in epithelial cancer cells, which are correlated with distant metastasis and cancer stem cell-like properties, are currently under active investigation. Noninfectious stimuli activating the IL- 6 signaling pathway lead to fibrosis through transglutaminase 2 (TG2) in pulmonary epithelial cells (unpublished data). As fibrosis and invasion of cancer have common characteristics [16], we propose that TG2 expressed in epithelial cancer cells might provide a similar connection.

TG2 has been implicated in the drug resistance and survival of cancer cells by modulating caspase- 3 and $\mathrm{NF}-\kappa \mathrm{B}$ activity [17-20] and in the in vitro migration and invasion of tumor cells through increased cell attachment via $\beta$-integrins and fibronectins with extracellular TG2 [21-23] and increases in matrix metalloprotease-2 (MMP-2) expression [24]. Peritoneal spreading of ovarian cancer cells [25] and tumor growth of pancreatic cancer [26] also parallel TG2 expression levels. Recently, correlation of TG2 expression and epithelial-tomesenchymal transition and invasion of cancer cells were reported for both breast and ovarian cancer cells $[27,28]$. However, a direct link between TG2 expression of primary tumors and distant hematogenous metastasis in animal models and cancer patients and cancer stem cell-like properties, which are related to cancer cell aggressiveness, has not been made.

In this study, we demonstrated that TG2 expression levels are correlated with cancer cell aggressiveness, and that the size and efficiency of tumor sphere formation was correlated with TG2 expression levels and was dependent on TG2-mediated IL-6 secretion in breast cancer cells. With highly immunocompromised mice, we evaluated the critical role of TG2 and downstream IL- 6 in the distant metastasis of breast cancer cells. Moreover, TG2 expression in primary tumor tissue was inversely correlated with recurrence-free survival and distant metastasis-free survival (DMFS) in patients with breast cancer, evaluated from a tissue microarray of primary tumors. Furthermore, by using public datasets that included a total of 684 breast cancer patients, we found that the expression of TG2 and IL-6 was correlated in breast cancer patients and that the combined high expression of TG2 and IL- 6 was related to a poor DMFS outcome in breast cancer. Thus, in this study, we provide evidence that TG2 is an important link in IL-6mediated tumor aggressiveness and that TG2 could be an important mediator of distant metastasis in both a xenograft animal model and in patients with advanced breast cancer.

\section{Materials and methods}

\section{Cell lines and TG2- and IL-6-knockdown}

The human breast cancer cell lines were obtained from the American Type Culture Collection (Manassas, VA, USA). TG2-knocked-down MDA-MB-231 cells (shTG2_MB231) were established by using the shorthairpin RNA (shRNA) vector for TG2. The target sequence for TG2 was 5'-GGGCGAACCACC TGAACAA-3' [29]. In brief, MDA-MB-231 cells were co-transfected with the pcDNA3.1 plus pSUPER plasmid containing shRNA for TG2 by using Promofectin (PromoKine, Heidelberg, Germany), according to the manufacturer's instructions. Control cells were transfected with the pcDNA3.1 vector only. TG2-knockdown in selected clones was shown by Western blot analysis. IL6 production in MDA-MB-231 cells was inhibited by using the IL-6 shRNA vector (shIL-6). Cells transfected with the shIL- 6 vector were cultured in the presence of G418, and IL-6-knocked-down MDA-MB-231 (shIL6_MB231) clones were selected by performing an IL-6 enzyme-linked immunosorbent assay (ELISA).

\section{Western blot analysis}

Cells were harvested in a lysis solution containing $1 \%$ NP40, a protease inhibitor cocktail, and a phosphatase inhibitor (Sigma-Aldrich///). Proteins $(10 \mu \mathrm{g})$ were separated with SDS-PAGE, and transferred polyvinylidene difluoride membranes were probed with appropriate antibodies: anti-TG2 (Neomarkers, Fremont, CA, USA), anti- $\beta$-actin (Sigma-Aldrich), anti-Bcl-2, and anti-cIAP2 (Santa Cruz Biotechnology, Santa Cruz, CA, USA).

\section{ELISA and MTT assay}

In total, $1 \times 10^{4}$ cells were applied on 24-well plates and allowed to adhere overnight. Then the medium was replaced, and cells were permitted to grow for 24,48 , or 72 hours. To inhibit TG2 activity, some cells were treated with cysteamine (Sigma-Aldrich). Supernatants were collected and assayed to quantify soluble IL- 6 production by ELISA. All assays were performed in triplicate 
and were repeated 2 or 3 times under independent conditions. Data are presented as mean $\pm \mathrm{SD}$.

\section{Sphere formation}

Cells grown in an anchorage-independent condition were trypsinized and resuspended in serum-free medium consisting of a 1:1 mixture of F-12 Nutrient Mixture (Ham's F-12) and DMEM, supplemented with $20 \mathrm{ng} / \mathrm{ml}$ epithelial growth factor (Invitrogen, Carlsbad, CA, USA), $20 \mathrm{ng} / \mathrm{ml}$ basic fibroblast growth factor (Millipore, Billerica, MA, USA), $0.5 \mathrm{nM}$ hydrocortisone (SigmaAldrich), B-27 supplement (GIBCO), and $2 \mathrm{mM} \mathrm{L-gluta-}$ mine $(\mathrm{GIBCO} / / /)$. Cells were applied on nonadherent 96-well plates (Corning, Corning, NY, USA) at 10, 100, or $1,000 \mathrm{cells} / 100 \mu \mathrm{l} /$ well. To inhibit TG2 activity, cells were treated with cysteamine///. The medium was replaced every 3 days. Visible spheres were counted under a microscope on day 8 after plating.

\section{Animals and xenografts}

All mice were bred and maintained in specific pathogenfree conditions at the animal facility of Seoul National University College of Medicine. All animal experiments were performed with the approval of the institutional animal care and use committee of Seoul National University.

To assess tumorigenicity of the cancer cells, human breast cancer MDA-MB-231 cells were injected into the mammary fatpads into 8-week-old NOD/scid/IL-2R $\gamma^{-1-}$ (NOG) mice (Jackson Laboratory, Bar Harbor, ME, USA). Six weeks after the injection, the mice were killed, and primary tumor masses in the fatpads for breast cancer and lung were fixed in $4 \%$ paraformaldehyde for 24 hours. Sections $(4 \mu \mathrm{m})$ were stained with hematoxylin and eosin. The number of tumor masses in the liver and lung were counted under a dissecting microscope.

\section{Tissue microarray and immunohistochemistry}

To investigate the clinical significance of TG2 expression in human breast cancer tissue, TG2 expression was evaluated by immunohistochemistry in a tissue microarray. The tissue microarray was constructed from representative paraffin-embedded tumor tissues by an experienced breast pathologist. The array consisted of two cores per patient. The tissue microarray slides were stained with anti-TG2 (1:100, Neomarkers////). Antigen retrieval was facilitated by microwaving the tissue for 21 minutes, and the remainder of the staining procedure followed the standard avidin-biotinylated peroxidase complex method by using a commercial immunohistochemical kit (Envision-Kit; Dako, Carpinteria, CA, USA). The TG2 expression level in tumor tissue was determined by comparison with the TG2 expression in normal endothelial cells. Immunohistochemical staining was interpreted and categorized with an arbitrary semiquantitative scale as 0 (negative staining), $1+$ (equivalent to normal endothelial cell expression), and 2+ (more than normal endothelial cell expression) by a pathologist. Tumors showing TG2 expression (score, 2+) were categorized into a strong-TG2 group, and tumors showing 0 or 1+ TG2 expression, into a negative/weak-TG2 group for further statistical analysis. This study was approved by the Seoul National University Hospital institutional review board.

\section{Analysis of public human breast cancer gene expression datasets}

We collected three public mRNA expression datasets comprising a total of 684 breast cancer patients (GEO accession numbers: [GSE7390], [GSE11121], and [GSE2034]) [30-32]. The raw data were normalized by using the RMA approach, and final $\log _{2}$-transformed data were used for further analyses. Clinical data were downloaded from the same site. The level of TG2 expression was calculated by averaging the expression values of three probe sets (211003_x_at, 211573_x_at, and 216183_at). Survival was analyzed based on distant metastasis-free survival (DMFS) by using Kaplan-Meier curves and the log-rank test.

\section{Statistical analyses}

The IL- 6 production and cell-viability results are expressed as mean $\pm \mathrm{SD}$. A two-tailed Student $t$ test was used to compare measurements taken from the two samples. For in vivo experiments, differences in the numbers of tumor masses and tumor volume were analyzed by using a two-tailed Student $t$ test. A two-tailed $\chi^{2}$ test and Student $t$ test were used to compare nominal and continuous variables of the TG2 expression groups in the human breast cancer tissue microarray. Univariate survival analysis was performed with a Kaplan-Meier curve and the log-rank test. The Cox proportional hazard model was used for the survival analysis. All $P$ values $<0.05$ were deemed to indicate statistical significance. The SPSS software (ver. 11.0; SPSS Inc., Chicago, IL, USA) was used for all statistical analyses.

\section{Results}

\section{TG2 expression levels correlated with IL-6 production}

To evaluate the correlation between TG2 expression and biologic characteristics of cancer cells, we first analyzed TG2 expression in various human breast cancer cells encompassing luminal, basal A, and basal B types, according to their gene-expression profiles [33,34]. TG2 expression was confined to some basal A and all basal B cells tested, the most biologically aggressive types, but not in $\mathrm{ER}^{+}$or $\mathrm{ER}^{+/-} \mathrm{Her}-2^{+}$luminal types (Figure 1a). Next, we measured IL- 6 production from breast cancer 


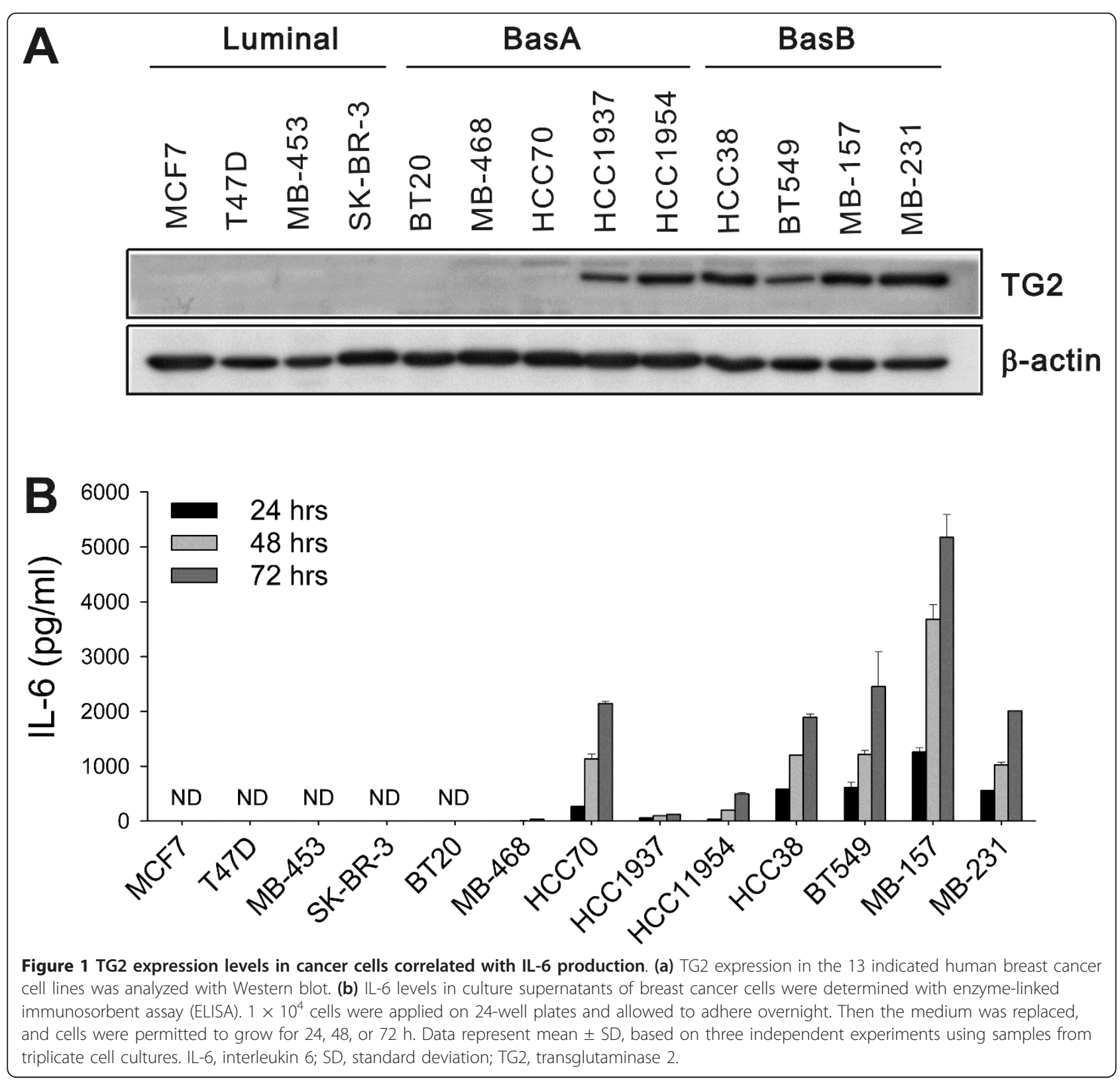

cell culture supernatants and found that cells expressing a high level of TG2 produced a large amount of IL-6. Some breast cancer cells neither expressed TG2 nor produced IL-6 (Figure 1b).

\section{TG2-knockdown reduced IL-6 production in breast cancer cells}

To evaluate whether modulation of TG2 expression levels in the given cancer cells leads to a change in IL-6 production, we compared IL-6 levels in control empty vectortransfected TG2 high-expressing cells, MDA-MB-231 (cont_MB231), and their TG2-knocked-down cells by using shRNA vectors (shTG2_MB231; Figure 2a).
shTG2_MB231 showed reduced IL-6 production, compared with cont_MB231 (Figure 2b). A causal link between TG2 activity and IL- 6 production was confirmed by using the TG2 inhibitor cysteamine. Inhibition of TG2 enzymatic activity reduced IL-6 production from TG2-highexpressing cells (Figure 2c). These findings indicate that TG2 is a key regulator of IL- 6 production in breast cancer cells. We also established IL-6-knocked-down breast cancer cells (shIL-6_MB231) by using the shIL-6 vector. The shIL-6_MB231 showed reduced IL-6 secretion, but revealed TG2 expression levels comparable to those of control cells (Figure 2d). Thus IL-6 production was downstream of TG2 activity in the breast cancer cells. 


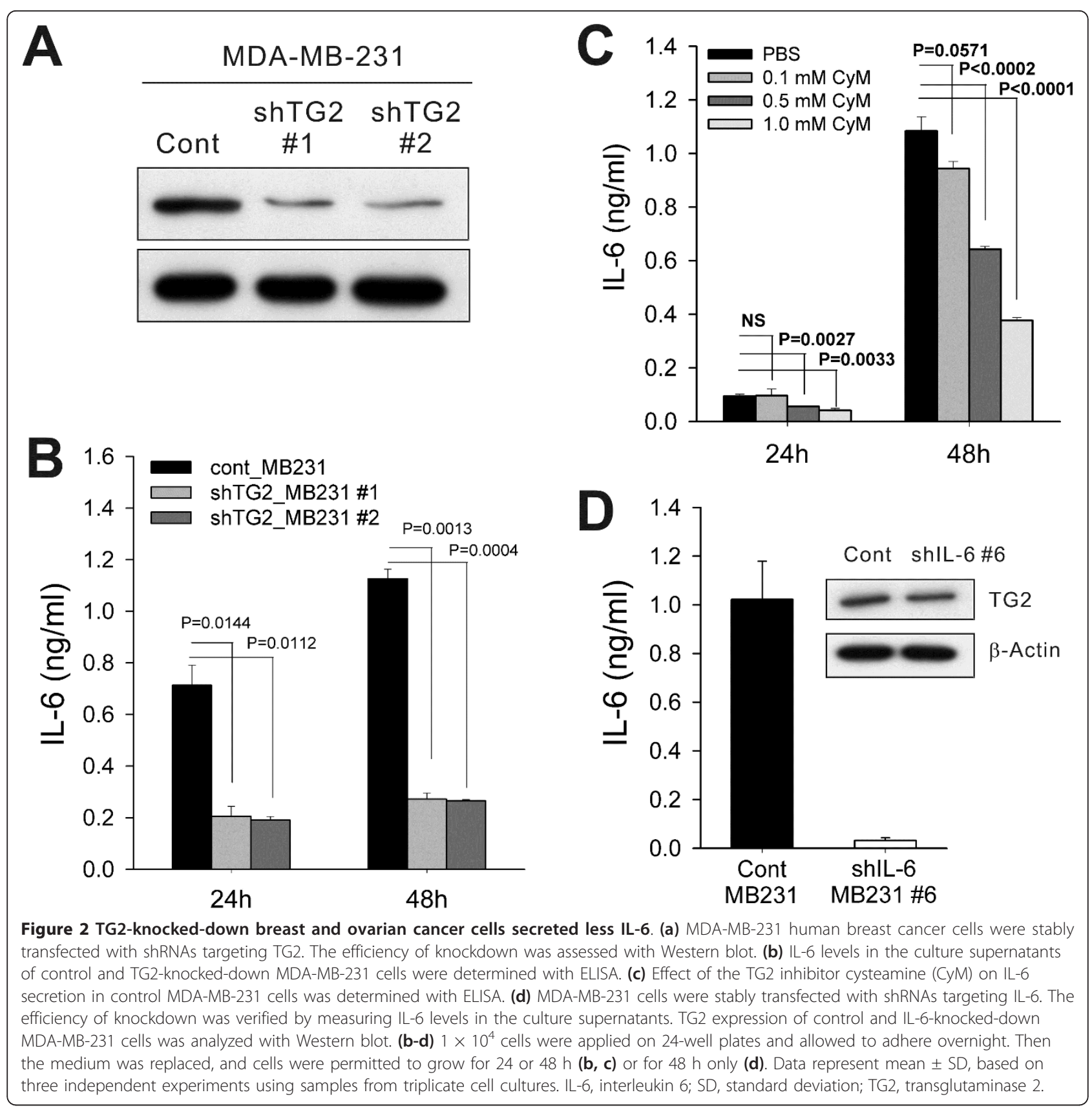

\section{Anchorage-independent survival of cancer cells was} dependent on TG2-mediated IL- 6 expression

TG2 expression endows aggressiveness and invasiveness to cancer cells through multiple effector pathways [35]. As tumor sphere formation and tumor cell aggressiveness are correlated [36] and IL-6 in tumor cells triggers malignant features in tumor spheres [15], we evaluated whether TG2 and downstream IL-6 were involved in tumor-sphere formation in vitro. Sphere formation decreased markedly both in TG2-knocked-down and IL6-knocked-down breast cancer cells (shTG2_MB231\#1 and shIL-6_MB231\#6, respectively) compared with the control empty vector-transfected cells (Figure $3 \mathrm{a}$ and $3 \mathrm{~b})$. The numbers and sizes of the spheres were reduced both in TG2-knocked-down and IL-6-knocked-down cells (Figure 3a and 3b). Compared with TG2-knockeddown cells (shTG2_MB231\#1), control cancer cells (cont_MB231) cultured in sphere medium expressed more antiapoptotic molecules, such as cIAP2 and Bcl-2 (Figure 3c). These data indicate that TG2 supported cell survival in an anchorage-independent condition. In addition, control cancer cells expressed more epithelial-to- 


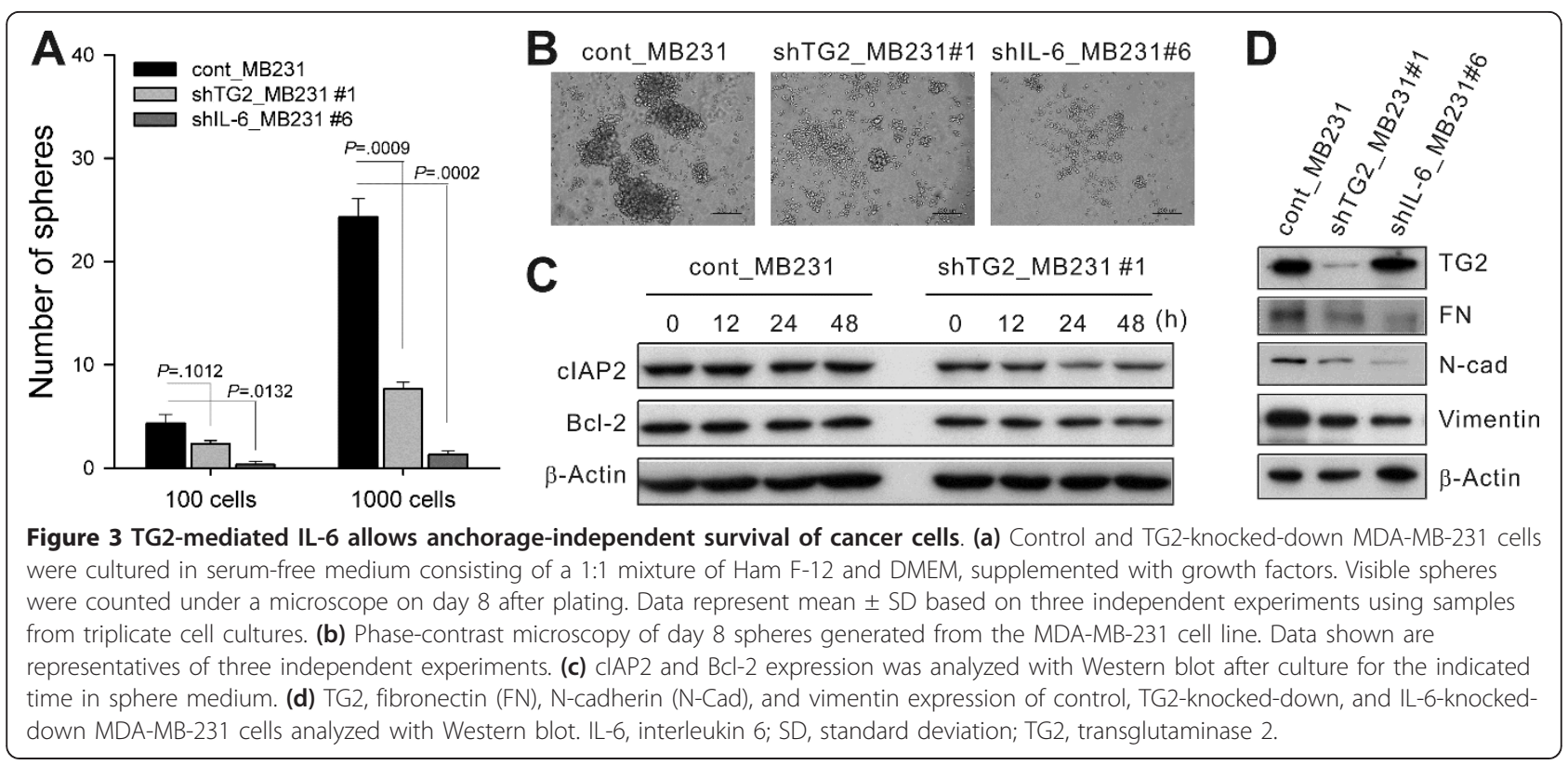

mesenchymal transition (EMT)-related molecules such as $\mathrm{N}$-cadherin and vimentin, compared with either TG2-knocked-down (shTG2_MB231\#1) or IL-6knocked-down cells (shIL-6_MB231\#6) (Figure 3d).

TG2 and downstream IL-6 facilitate tumor growth and distant liver and lung metastasis of breast cancer cells Previous results demonstrated that high TG2 expression resulted in high IL-6 expression, which was correlated with increased anchorage-independent growth. To evaluate the role of TG2 and downstream IL- 6 in tumor cell behavior in vitro, the effect of TG2 and its downstream IL-6 on in vivo tumor spreading and distant metastasis was evaluated by using highly immunocompromised NOD/scid/IL-2R $\gamma$ chain-deficient (NOG) mice, which completely lack NK activity, as well as T- and Bcell activity, as recipients [37].

Breast cancer cells with high TG2 levels (cont_MB231) showed rapid growth of primary tumor masses in the mammary fatpads compared with TG2-knocked-down cells (shTG2_MB231\#1, Figure 4a and 4c) and IL-6knocked-down cells (shIL-6_MB231\#6, Figure 4b and 4c). Notably, all the mice injected with IL-6-knockeddown cells showed no tumor mass formation at all in the fatpads up to 45 days after tumor inoculation (Figure $4 \mathrm{~b}$ and $4 \mathrm{c}$ ). More interestingly, our highly immunocompromised NOG mice inoculated with TG2-high-expressing cont_MB231 showed spontaneous distant hematogenous metastases, revealing multiple visible tumor masses in the lung parenchyma (Figure $4 \mathrm{~d}$ ). In contrast, much reduced lung metastasis was noted from mice injected with TG2-knocked-down cells (shTG2_MB231\#1), and no metastasis, with IL-6-knocked-down cells (shIL6_MB231\#6) (Figure 4d).

\section{TG2 expression predicted recurrence and metastasis in patients with breast cancer}

The clinical implications of TG2 expression in human breast cancer primary tumor tissue were examined with a tissue microarray from 443 patients with operable breast cancer treated at Seoul National University Hospital between February 2000 and December 2002. Among them, 31 patients were excluded because their microarray core did not contain breast tumor tissue or the tissue was detached during the immunostaining process, leaving 412 patients for the final analysis. The mean follow-up duration was 83.6 months $( \pm 29.8$ months). Forty-two (10.2\%) patients showed strong TG2 expression, compared with control endothelial cells (Figure 5a). The TG2 expression level was not significantly associated with known breast cancer prognostic factors, such as tumor size, lymph node metastasis, age, or estrogen-receptor status (Additional file 1 Table S1). However, patients with TG2-upregulated tumors had significantly shorter recurrence-free survival and distant metastasis-free survival $(P=0.019$ and $P=0.006$, respectively; Figure $5 \mathrm{~b}$ and $5 \mathrm{c}$ ) than those who did not. The TG2 expression level remained an independent prognostic factor predicting recurrence and distant metastasis after adjusting for known prognostic factors by using a Cox proportional hazard model (Figure $5 \mathrm{~d}$ ). These findings suggest that TG2 in human breast cancer primary tumor may play a critical role in cancer cell metastasis and recurrence. 

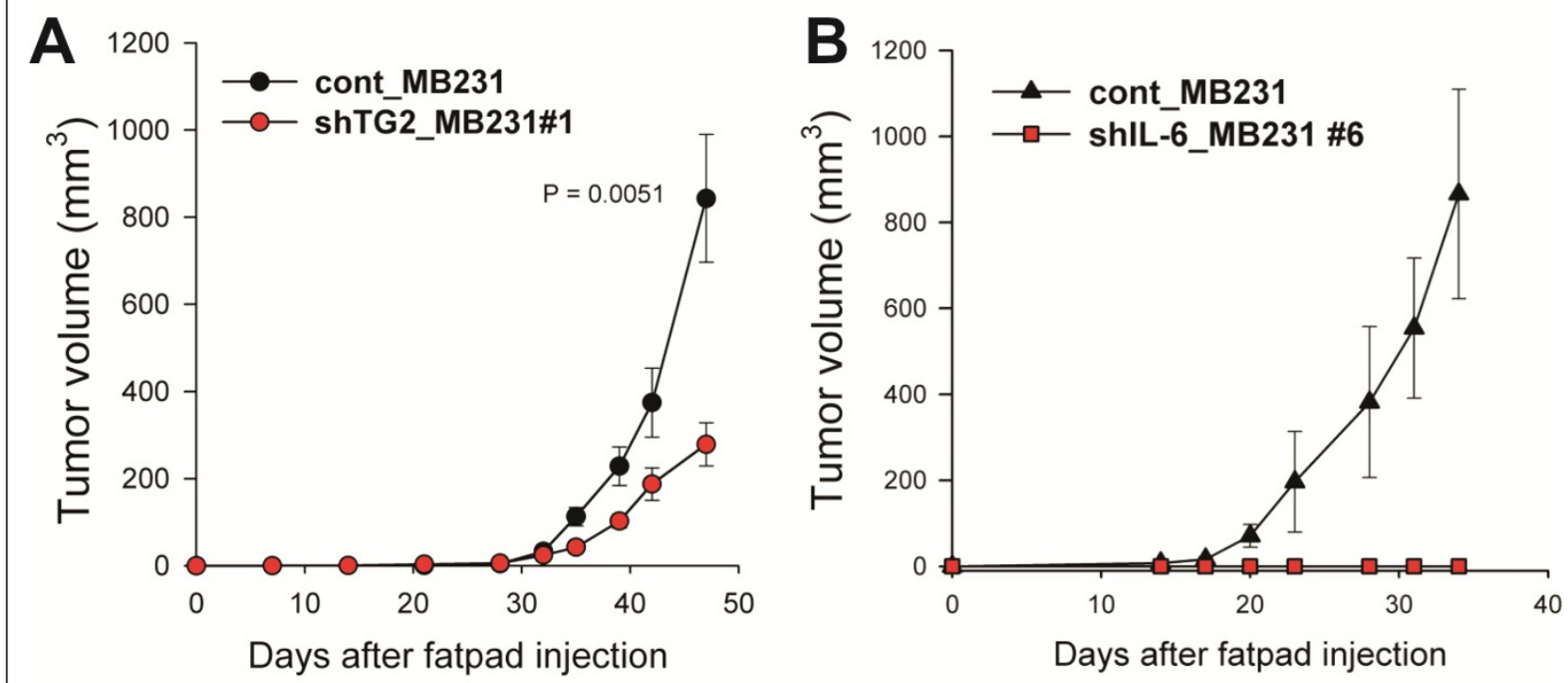

C

$$
\text { cont_MB231 }
$$

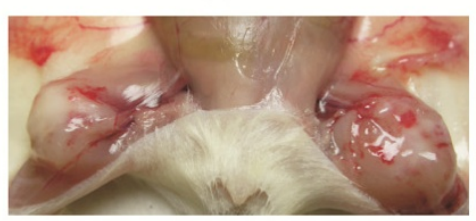

D

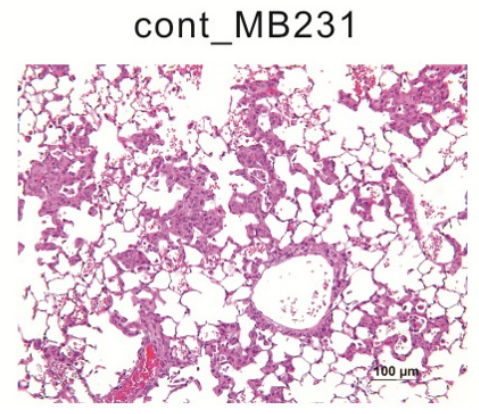

shTG2_MB231\#1

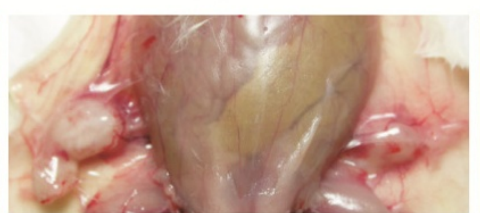

shTG2_MB231\#1

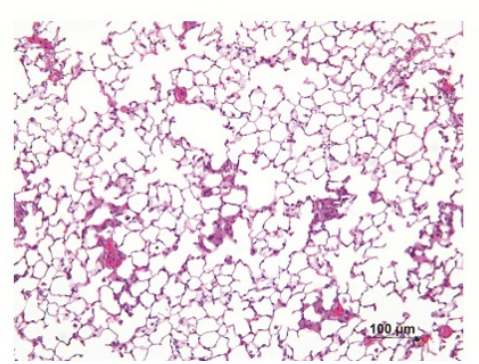

shIL-6_MB231\#6

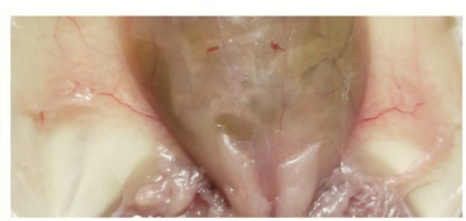

shIL-6_MB231\#6

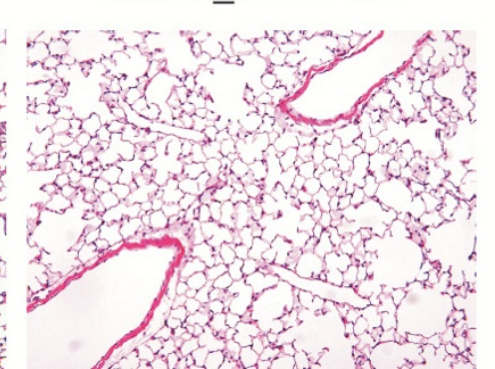

Figure 4 TG2-knocked-down and IL-6-knocked-down breast cancer cells revealed decreased tumor formation and distant metastasis (a) Control and TG2-knocked-down MDA-MB-231 cells $\left(2 \times 10^{5}\right.$ cells/each mouse) were injected in the fatpads of NOG mice. The growth of primary tumors was measured. (b) Control and IL-6-knocked-down MDA-MB-231 cells ( $2 \times 10^{5}$ cells/each mouse) were injected in the fatpads of NOG mice. The growth of primary tumors was measured. $(\mathbf{a}, \mathbf{b})$ Data are given as mean \pm SD of 14 mice for each group from two independent experiments. (c, d) At 45 days after the inoculation of cancer cells, the mice were killed, and the primary tumor masses in the fatpads and distant metastases in the liver, lung, and other organs were analyzed. (c) Tumor formation in the fatpads of mice xenografted with MDA-MB-231 cells. (d) Lung sections from mice xenografted with MDA-MB-231 cells were obtained and stained with hematoxylin and eosin (original magnification, $\times 200$ ). (c, d) Data shown are representatives of each group. IL-6, interleukin 6; NOG, NOD/scid/IL-2Ry chain-deficient; SD, standard deviation; TG2, transglutaminase 2 .

In the previous section, we demonstrated that the expression of TG2 and IL-6 was correlated and that high TG2 expression was associated with a high proportion of distant metastasis and larger primary tumors in a mouse xenograft model. To confirm this relation in patient clinical data, public datasets that included a total of 684 breast cancer patients were collected, and the association between DMFS and TG2/IL-6 expression 
A
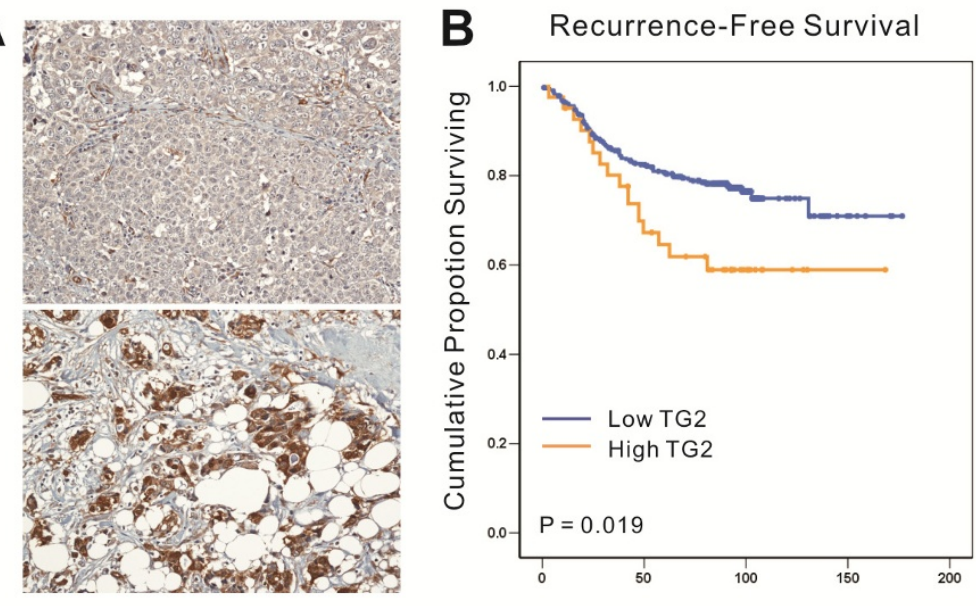

C Distant Metastasis-Free Survival

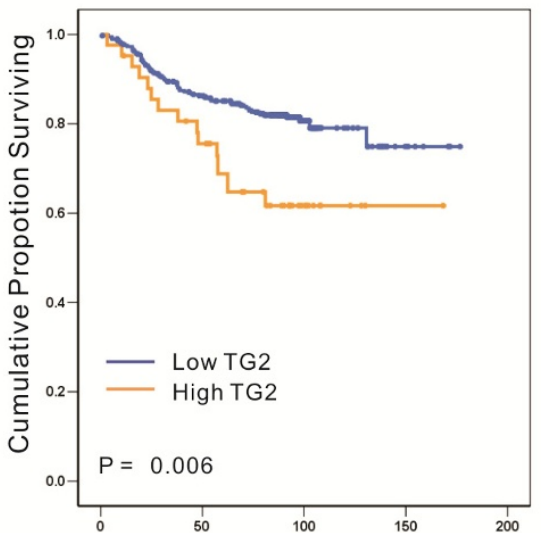

D Cox's proportional hazards regression models for recurrence-free survival and distant metastasis-free survival

\begin{tabular}{|c|c|c|c|c|c|c|}
\hline \multirow{2}{*}{ Variable } & \multicolumn{3}{|c|}{ Recurrence-free survival } & \multicolumn{3}{|c|}{ Distant metastasis-free survival } \\
\hline & $\mathrm{HR}$ & $95 \% \mathrm{Cl}$ & $P$ value & $\mathrm{HR}$ & $95 \% \mathrm{Cl}$ & $P$ value \\
\hline TG2 expression & 1.91 & 1.11 to 3.30 & .020 & 2.15 & 1.21 to 3.80 & .009 \\
\hline Lymph node positive & 2.66 & 1.68 to 4.21 & $<.001$ & 3.12 & 1.85 to 5.26 & $<.001$ \\
\hline Tumor size, $>2$ & 2.42 & 1.31 to 4.48 & .005 & 3.80 & 1.70 to 8.50 & .001 \\
\hline Hormone receptor negative & 1.76 & 1.17 to 2.64 & .007 & 1.81 & 1.16 to 2.81 & .009 \\
\hline Age, $<35$ & 1.48 & 0.87 to 2.51 & .015 & 1.46 & 0.81 to 2.61 & .204 \\
\hline
\end{tabular}

Figure 5 TG2 expression predicts recurrence and metastasis in patients with breast cancer. TG2 expression was analyzed with immunohistochemistry in a tissue microarray of primary tumors from patients with advanced breast cancer. (a) Immunohistochemical staining for TG2 in the primary tumors of patients with breast cancer showing negative (upper) and strong expression (lower) ( $\times 200)$. (b) Recurrence-free survival and (c) distant metastasis-free survival according to TG2 expression adjusted for tumor size ( $\leq 2 \mathrm{~cm}$ versus $>2 \mathrm{~cm})$, histologic grade $(1,2$ versus 3), lymph node status (positive versus negative), and hormone-receptor status (positive versus negative). The mean follow-up duration for patients after surgery was $83.6 \pm 29.8$ months. (d)/////Table 1. Cox's proportional hazards regression models for recurrence-free and distant metastasis-free survival. TG2, transglutaminase 2 .

was investigated. First, the patients were stratified into three groups based on the level of IL-6 expression: high (patients with $\geq 67 \%$ IL-6 expression), medium (33 67\%), and low IL-6 ( $\leq 33 \%)$ (Figure 6a). Subsequently, the patients in each group were further stratified into two groups according to the level of TG2 expression: low TG2 included patients with $\leq 33 \%$ expression level of TG2, and high TG2 included all other patients (Figure 6b). Finally, the survival analysis revealed that in the high IL-6 group, most of the patients expressed high levels of TG2 $(n=181)$, and only $20 \%$ of the patients $(n=45)$ expressed low levels of TG2 (Figure 6c). In addition, high TG2 was associated with a significantly $(P=0.013)$ shorter DMFS compared with low TG2 in this group. However, no significant survival differences were detected between the high- and low-TG2 groups in the low- or medium-IL-6 groups (Figure 6d and 6e). Conversely, the proportion of patients with low TG2 expression increased as the expression of IL-6 decreased (Figure 6c through 6e), indicating that the expression of TG2 and IL- 6 is also correlated in breast cancer patients. In conclusion, combined high expression of TG2 and IL-6 was related to a poor DMFS outcome in breast cancer.

\section{Discussion}

Tumor metastasis is one of the most serious and relevant problems in tumor treatment. The formation of 


\section{Oh et al Figure 6}
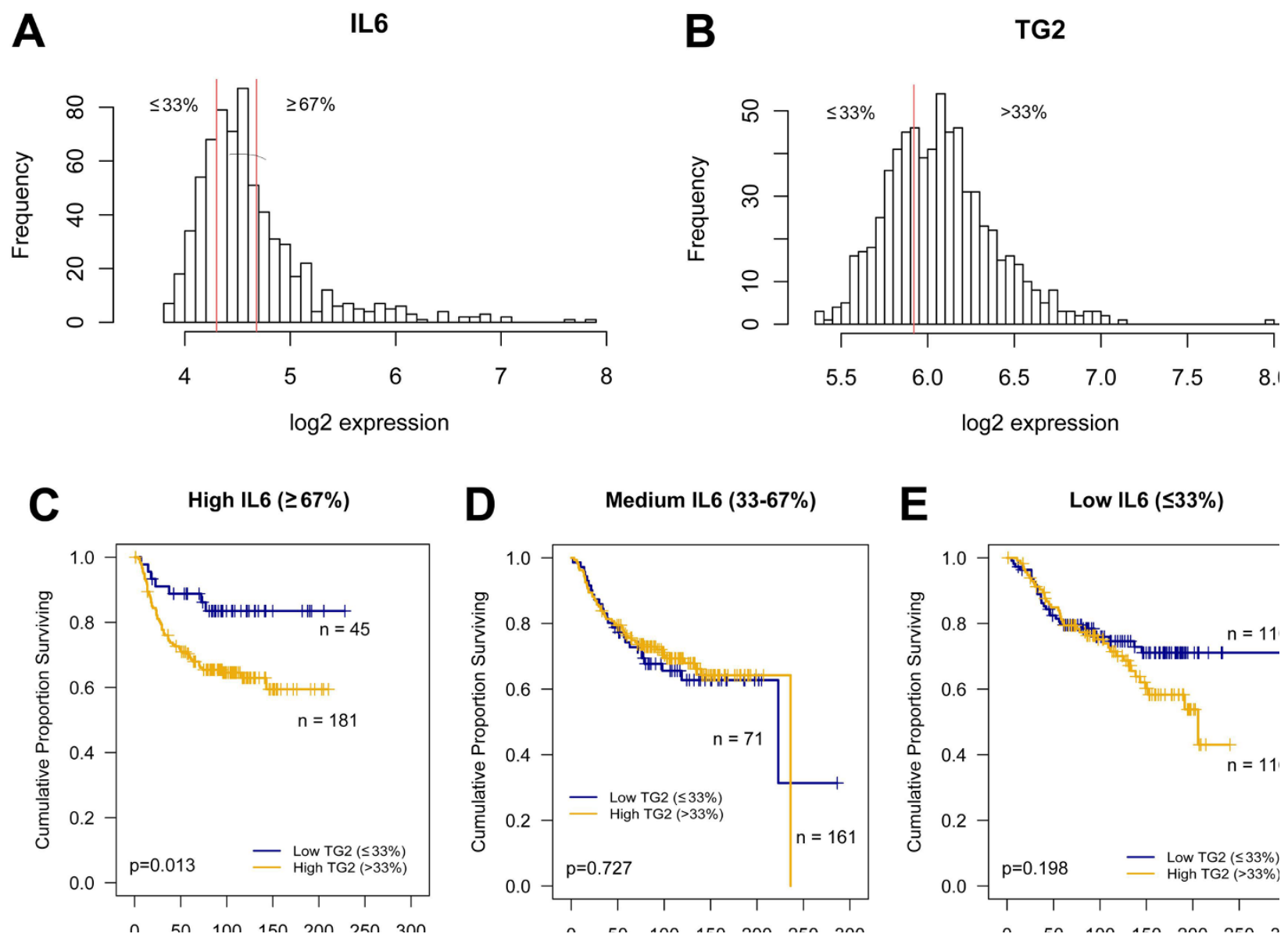

Figure 6 Expression of TG2 and IL- 6 in patients with breast cancer and their relation to distant metastasis-free survival. In total, 684 human breast cancer gene-expression profiles were obtained from three public datasets, and the association between the expression of TG2/L6 and distant metastasis-free survival (DMFS) was analyzed. The distributions of the $\log _{2}$ expression levels of IL-6 (a) and TG2 (b). DMFS according to TG2 expression in the patients with high (c), medium (d), and low (e) IL-6 expression. IL-6, interleukin 6; TG2, transglutaminase 2.

metastases is a complex process, which requires the action of various effectors not yet completely identified. In this study, we found that TG2 expression in tumor cells is essential for tumor growth, invasion, and distant hematogenous metastasis. Furthermore, a tissue microarray analysis of 412 patients with advanced breast cancer and a 7-year follow-up revealed that TG2 expression in primary tumor tissue is correlated with recurrencefree survival and distant metastasis-free survival.

Cancer-sphere formation is an in vitro assay to detect a cancer cell subpopulation that shows anchorage-independent growth in vitro and in vivo tumorigenesis [15], called cancer-initiating cells. For distant metastasis, detached cells from the tumor microenvironments enter the circulation. The survival of circulating cells is affected by inflammatory cytokines, such as tumor necrosis factor alpha (TNF- $\alpha$ ) and IL-6 [38]. TNF- $\alpha$ has controversial effects in cancer pathogenesis, including induction of apoptosis or EMT of tumor cells $[39,40]$. IL-6 is produced from epithelial tumor cells themselves as well as stromal cells, and cancer-derived IL-6 induces a cancer stem cell-like phenotype in these cells [15]. Moreover, sustained activation of STAT3, a downstream IL-6 signaling mediator, is important for stem cell selfrenewal $[41,42]$.

In this study, in vitro tumor-sphere formation of breast cancer cells was largely dependent on TG2 expression and was inhibited by a TG2 enzymatic inhibitor. IL-6 production from cancer cells was dependent on TG2 expression, and tumor-sphere formation was correlated with TG2-dependent IL-6 production in cancer cells, indicating that the effect of TG2 on tumorsphere formation is mediated through downstream IL-6 production. A correlation between in vitro tumor-sphere 
formation and in vivo tumorigenesis was confirmed in breast cancer cells, and TG2 expression and downstream IL-6 production were profoundly correlated with primary tumor growth of the human breast cancer cells in the mammary fatpads.

In vivo tumor invasion and metastasis of epithelial cancer cells has recently been associated with EMT of tumor epithelial cells [43]. TGF- $\beta$ and downstream Snails, Twists, and ZEBs are associated with EMT phenotypes [44]. IL-6 has also been implicated in the induction of the breast cancer cell EMT phenotype [14], and recent reports suggest the role of TG2 in the EMT phenomena of both breast and ovarian cancer cells $[27,28]$. Thus, TG2 and downstream IL- 6 may be important in the EMT of epithelial cancer cells and associated with in vivo invasiveness and distant metastasis of these cells.

With the advantage of using highly immunocompromised mice, we constructed a spontaneous distant metastasis model by using TG2-high-expressing MDAMB-231 human breast cancer cells implanted in the orthotopic mammary fatpads. Forty-five days after implantation of control MDA-MB-231 cells, all the mice showed visible lung metastases. Lung metastases were decreased in the mice xenografted with TG2-knockeddown cells, and none of the mice xenografted with IL-6knocked-down cells showed distant metastases. Thus TG2 and downstream IL- 6 produced from epithelial breast cancer cells facilitated distant hematogenous lung metastases of these cells.

In this study, the TG2 and downstream IL-6 signaling pathway may act as a convergence site for EMT and cancer-initiating cell phenotypes, leading to enhanced local tumor growth and distant hematogenous metastasis. Thus, targeting either TG2 or downstream IL- 6 would be a very efficient strategy to inhibit primary tumor growth and distant hematogenous metastasis of breast cancer cells. Complete inhibition of primary tumor growth and distant lung metastasis by IL-6-knockdown compared with some residual tumor growth and metastases by TG2-knockdown in the breast cancer cells. In addition to the IL-6 signaling pathway, TG2 can directly modulate the extracellular matrix (ECM) structure [45], activate focal adhesion kinase via binding with integrins [35], and activate growth factors such as TGF- $\beta$ [46], a key inducer of EMT, buried in the ECM networks, and thus may affect a broader aspect of tumor biology.

The clinical significance of TG2 expression in breast cancer has been reported; TG2 is upregulated in epithelial and stromal cells of tumor tissue [47], and lymph node metastatic tumors show significantly higher TG2 expression levels than do primary tumors in the same patients [48]. In patients with ovarian cancer, TG2 is upregulated in cancer tissue compared with the normal counterpart [25], and TG2 overexpression is associated with high tumor stage [49]. However, a direct clinical correlation between TG2 expression in primary tumor and distant metastasis in patients is not available.

In this study, we assessed the correlation between TG2 expression in primary breast cancer tissue and distant metastasis by analyzing a tissue microarray of 412 patients and their metastasis status for approximately 7 years (mean follow-up duration, $83.6 \pm 29.8$ months). Although the overall survival rate of breast cancer patients did not correlate with TG2 expression levels, patients with TG2-upregulated tumors showed significantly shorter relapse-free survival and distant metastasis-free survival, after adjusting for known prognostic factors such as tumor size, lymph node metastasis, age, and hormone-receptor status. Thus, TG2 was an independent prognostic factor predicting recurrence and distant metastasis in patients with breast cancer. As increased TG2 expression has also been reported in metastatic tumor tissue [48], we propose that TG2 is an important mediator and/or prognostic marker for distant metastasis, affecting both cancer-initiating cell-like and EMT phenotypes. Thus, intervention specific to TG2 in epithelial cancer cells could provide a promising means of controlling tumor metastasis.

\section{Conclusions}

We have observed that differential TG2 expressions of cancer cells were dictated into their IL- 6 production, and TG2 and downstream IL-6 production from cancer cells wase correlated with their capacity for tumorsphere formation in vitro. Primary tumor growth in the mammary fatpads and distant hematogenous metastasis of breast cancer cells into the lung was also dependent on TG2 and downstream IL-6 expression levels. We also found that TG2 expression in primary tumor tissue is inversely correlated with recurrence-free survival $(P=$ $0.019)$ and distant metastasis-free survival $(P=0.006)$ in patients with advanced breast cancer. Thus, TG2 expression in cancer cells is an important link in IL-6mediated tumor aggressiveness, and TG2 could be an important mediator of distant metastasis, both in a xenograft animal model and in patients with advanced breast cancer.

\section{Additional material}

Additional file 1: Table S1. Association between TG2 expression and other clinicopathologic factors.

\section{Abbreviations}

EMT: epithelial-to-mesenchymal transition; IL-6: interleukin-6; MMP-2: matrix metalloprotease-2; NF-kB: nuclear factor (NF)-KB; NOG: NOD/scid/IL-2RY chain-deficient; TG2: transglutaminase 2; TNF-a: tumor necrosis factor alpha. 


\section{Acknowledgements}

This research was supported by grants from MarineBio Technology Project funded by the Ministry of Land, Transport and Maritime Affairs (d-s.l.) and from Korea Healthcare technology R\&D Project funded by the Ministry for Health, Welfare \& Family Affairs (No. A084022) (d-s.l.). We thank Prof. Hyunggee Kim at Korea University and Prof. In-Gyu Kim at Seoul National University, Korea, for kindly providing the shRNA vector for IL-6 and TG2, respectively.

\section{Author details}

'Laboratory of Immunology, Interdisciplinary Program of Tumor Biology, Cancer Research Institute, Seoul National University College of Medicine, 28 Yongon-dong Chongno-gu, Seoul 110-799, Korea. ${ }^{2}$ Transplantation Research Institute, Seoul National University College of Medicine, 28 Yongon-dong Chongno-gu, Seoul 110-799, Korea. ${ }^{3}$ Department of Surgery, Seoul National University College of Medicine, 28 Yongon-dong Chongno-gu, Seoul 110799, Korea. ${ }^{4}$ Dongnam Institute of Radiological \& Medical Sciences, 40 Jwadong-gil Jangan-eup, Gijang-gun, Busan 619-953, Korea. ${ }^{5}$ Department of Pathology, Hanil Hospital, 388-1 Sangmon3-dong Dobong-gu, Seoul 132-703, Korea. ${ }^{6}$ College of Pharmacy, Sunchon National University, 255 Jungangno, Suncheon, Jeonnam 540-742, Korea.

\section{Authors' contributions}

$\mathrm{KO}$ conducted most of the experiments and contributed to the planning and analysis. EK and HGM generated TMA and conducted clinical follow-up. HSK scored TMA. DYN helped design the study. DSL was responsible for the overall direction of the project. All authors have read and approved the manuscript for publication.

\section{Competing interests}

The authors declare that they have no competing interests.

\section{Received: 24 February 2011 Revised: 18 August 2011}

Accepted: 3 October 2011 Published: 3 October 2011

\section{References}

1. Shankaran V, Ikeda H, Bruce AT, White JM, Swanson PE, Old LJ, Schreiber RD: IFNgamma and lymphocytes prevent primary tumour development and shape tumour immunogenicity. Nature 2001, 410:1107-1111.

2. Grivennikov SI, Greten FR, Karin M: Immunity, inflammation, and cancer. Cell 2010, 140:883-899.

3. Polk DB, Peek RM Jr: Helicobacter pylori: gastric cancer and beyond. Nat Rev Cancer 2010, 10:403-414.

4. Tsai WL, Chung RT: Viral hepatocarcinogenesis. Oncogene 2010, 29:2309-2324.

5. Park EJ, Lee JH, Yu GY, He G, Ali SR, Holzer RG, Osterreicher CH, Takahashi H, Karin M: Dietary and genetic obesity promote liver inflammation and tumorigenesis by enhancing IL-6 and TNF expression. Cell 2010, 140:197-208.

6. Khasawneh J, Schulz MD, Walch A, Rozman J, Hrabe de Angelis M, Klingenspor M, Buck A, Schwaiger M, Saur D, Schmid RM, Klöppel G, Sipos B, Greten FR, Arkan MC: Inflammation and mitochondrial fatty acid beta-oxidation link obesity to early tumor promotion. Proc Natl Acad Sci USA 2009, 106:3354-3359.

7. Mantovani A, Allavena P, Sica A, Balkwill F: Cancer-related inflammation. Nature 2008, 454:436-444.

8. López-Novoa JM, Nieto MA: Inflammation and EMT: an alliance towards organ fibrosis and cancer progression. EMBO Mol Med 2009, 1:303-314.

9. Karin $\mathrm{M}$ : Nuclear factor- $\mathrm{kB}$ in cancer development and progression. Nature 2006, 441:431-436.

10. Knüpfer H, Preiss R: Significance of interleukin-6 (IL-6) in breast cancer. Breast Cancer Res Treat 2007, 102:129-135.

11. Bachelot T, Ray-Coquard I, Menetrier-Caux C, Rastkha M, Duc A, Blay JY: Prognostic value of serum levels of interleukin 6 and of serum and plasma levels of vascular endothelial growth factor in hormonerefractory metastatic breast cancer patients. Br J Cancer 2003, 88:1721-1726.

12. Grivennikov S, Karin E, Terzic J, Mucida D, Yu GY, Vallabhapurapu S, Scheller J, Rose-John S, Cheroutre H, Eckmann L, Karin M: IL-6 and Stat3 are required for survival of intestinal epithelial cells and development of colitis-associated cancer. Cancer Cell 2009, 15:103-113.

13. Huber MA, Azoitei N, Baumann B, Grünert S, Sommer A, Pehamberger $H$ Kraut N, Beug $H$, Wirth T: NF-kB is essential for epithelial-mesenchymal transition and metastasis in a model of breast cancer progression. $J$ Clin Invest 2004, 114:569-581.

14. Sullivan NJ, Sasser AK, Axel AE, Vesuna F, Raman V, Ramirez N, Oberyszyn TM, Hall BM: Interleukin-6 induces an epithelial-mesenchymal transition phenotype in human breast cancer cells. Oncogene 2009, 28:2940-2947.

15. Sansone P, Storci G, Tavolari S, Guarnieri T, Giovannini C, Taffurelli M, Ceccarelli C, Santini D, Paterini P, Marcu KB, Chieco P, Bonafè M: IL-6 triggers malignant features in mammospheres from human ductal breast carcinoma and normal mammary gland. J Clin Invest 2007, 117:3988-4002.

16. Schäfer M, Werner S: Cancer as an overhealing wound: an old hypothesis revisited. Nat Rev Mol Cell Biol 2008, 9:628-638.

17. Antonyak MA, Miller AM, Jansen JM, Boehm JE, Balkman CE, Wakshlag JJ, Page RL, Cerione RA: Augmentation of tissue transglutaminase expression and activation by epidermal growth factor inhibit doxorubicin-induced apoptosis in human breast cancer cells. J Biol Chem 2004, 279:41461-41467.

18. Kim DS, Park SS, Nam BH, Kim IH, Kim SY: Reversal of drug resistance in breast cancer cells by transglutaminase 2 inhibition and nuclear factorkappaB inactivation. Cancer Res 2006, 66:10936-10943.

19. Cao L, Petrusca DN, Satpathy M, Nakshatri H, Petrache I, Matei D: Tissue transglutaminase protects epithelial ovarian cancer cells from cisplatininduced apoptosis by promoting cell survival signaling. Carcinogenesis 2008, 29:1893-1900.

20. Jang GY, Jeon JH, Cho SY, Shin DM, Kim CW, Jeong EM, Bae HC, Kim TW, Lee SH, Choi Y, Lee DS, Park SC, Kim IG: Transglutaminase 2 suppresses apoptosis by modulating caspase 3 and NF-kappaB activity in hypoxic tumor cells. Oncogene 2010, 29:356-367.

21. Verderio EA, Telci D, Okoye A, Melino G, Griffin M: A novel RGDindependent cell adhesion pathway mediated by fibronectin-bound tissue transglutaminase rescues cells from anoikis. J Biol Chem 2003, 278:42604-42614.

22. Mangala LS, Fok JY, Zorrilla-Calancha IR, Verma A, Mehta K: Tissue transglutaminase expression promotes cell attachment, invasion and survival in breast cancer cells. Oncogene 2007, 26:2459-2470.

23. Antonyak MA, Li B, Regan AD, Eng Q, Dusaban SS, Cerione RA: Tissue transglutaminase is an essential participant in the epidermal growth factor-stimulated signaling pathway leading to cancer cell migration and invasion. J Biol Chem 2009, 284:17914-17925.

24. Satpathy M, Shao M, Emerson R, Donner DB, Matei D: Tissue transglutaminase regulates matrix metalloproteinase-2 in ovarian cancer by modulating CAMP-response element-binding protein activity. $J$ Biol Chem 2009, 284:15390-15399.

25. Satpathy M, Cao L, Pincheira R, Emerson R, Bigsby R, Nakshatri H, Matei D: Enhanced peritoneal ovarian tumor dissemination by tissue transglutaminase. Cancer Res 2007, 67:7194-7202.

26. Verma A, Guha S, Diagaradjane P, Kunnumakkara AB, Sanguino AM, LopezBerestein G, Sood AK, Aggarwal BB, Krishnan S, Gelovani JG, Mehta K: Therapeutic significance of elevated tissue transglutaminase expression in pancreatic cancer. Clin Cancer Res 2008, 14:2476-2483.

27. Kumar A, Xu J, Brady S, Gao H, Yu D, Reuben J, Mehta K: Tissue transglutaminase promotes drug resistance and invasion by inducing mesenchymal transition in mammary epithelial cells. PLoS One 2010, 5 : e13390.

28. Shao M, Cao L, Shen C, Satpathy M, Chelladurai B, Bigsby RM, Nakshatri H, Matei D: Epithelial-to-mesenchymal transition and ovarian tumor progression induced by tissue transglutaminase. Cancer Res 2009, 69:9192-9201.

29. Brummelkamp TR, Bernards R, Agami R: A system for stable expression of short interfering RNAs in mammalian cells. Science 2002, 296:550-553.

30. Desmedt C, Piette F, Loi S, Wang Y, Lallemand F, Haibe-Kains B, Viale G, Delorenzi M, Zhang Y, Saghatchian M, Bergh J, Lidereau R, Ellis P, Harris A, Klijn JG, Foekens JA, Cardoso F, Piccart MJ, Buyse M, Sotiriou C: Strong time dependence of the 76-gene prognostic signature for node-negative breast cancer patients in the TRANSBIG multicenter independent validation series. Clin Cancer Res 2007, 13:3207-3214. 
31. Schmidt $M$, Böhm D, von Törne $C$, Steiner E, Puhl A, Pilch $H$, Lehr $H_{\text {, }}$ Hengstler JG, Kölbl H, Gehrmann M: The humoral immune system has a key prognostic impact in node-negative breast cancer. Cancer Res 2008, 68:5405-5413.

32. Wang Y, Klijn JG, Zhang Y, Sieuwerts AM, Look MP, Yang F, Talantov D, Timmermans M, Meijer-van Gelder ME, Yu J, Jatkoe T, Berns EM, Atkins D, Foekens JA: Gene-expression profiles to predict distant metastasis of lymph-node-negative primary breast cancer. Lancet 2005, 365:671-679.

33. Perou CM, Sørlie T, Eisen MB, van de Rijn M, Jeffrey SS, Rees CA, Pollack JR, Ross DT, Johnsen H, Akslen LA, Fluge O, Pergamenschikov A, Williams $C$, Zhu SX, Lønning PE, Børresen-Dale AL, Brown PO, Botstein D: Molecular portraits of human breast tumours. Nature 2000, 406:747-752.

34. Neve RM, Chin K, Fridlyand J, Yeh J, Baehner FL, Fevr T, Clark L, Bayani N, Coppe JP, Tong F, Speed T, Spellman PT, DeVries S, Lapuk A, Wang NJ, Kuo WL, Stilwell JL, Pinkel D, Albertson DG, Waldman FM, McCormick F, Dickson RB, Johnson MD, Lippman M, Ethier S, Gazdar A, Gray JW: A collection of breast cancer cell lines for the study of functionally distinct cancer subtypes. Cancer Cell 2006, 10:515-527.

35. Mehta K: Biological and therapeutic significance of tissue transglutaminase in pancreatic cancer. Amino Acids 2009, 36:709-716.

36. Sodek KL, Ringuette MJ, Brown TJ: Compact spheroid formation by ovarian cancer cells is associated with contractile behavior and an invasive phenotype. Int J Cancer 2009, 124:2060-2070.

37. Ito M, Hiramatsu H, Kobayashi K, Suzue K, Kawahata M, Hioki K, Ueyama Y, Koyanagi Y, Sugamura K, Tsuji K, Heike T, Nakahata T: NOD/SCID/gamma(c) (null) mouse: an excellent recipient mouse model for engraftment of human cells. Blood 2002, 100:3175-3182.

38. Kim MY, Oskarsson T, Acharyya S, Nguyen DX, Zhang XH, Norton L, Massagué J: Tumor self-seeding by circulating cancer cells. Cell 2009, 139:1315-1326.

39. Daniel D, Wilson NS: Tumor necrosis factor: renaissance as a cancer therapeutic? Curr Cancer Drug Targets 2008, 8:124-131.

40. Takahashi E, Nagano O, Ishimoto T, Yae T, Suzuki Y, Shinoda T, Nakamura S, Niwa S, Ikeda S, Koga H, Tanihara H, Saya H: Tumor necrosis factor-alpha regulates transforming growth factor-beta-dependent epithelialmesenchymal transition by promoting hyaluronan-CD44-moesin interaction. J Biol Chem 2010, 285:4060-4073.

41. Chung YJ, Park BB, Kang YJ, Kim TM, Eaves CJ, Oh IH: Unique effects of Stat3 on the early phase of hematopoietic stem cell regeneration. Blood 2006, 108:1208-1215.

42. Müller S, Chakrapani BP, Schwegler H, Hofmann HD, Kirsch M: Neurogenesis in the dentate gyrus depends on ciliary neurotrophic factor and signal transducer and activator of transcription 3 signaling. Stem Cells 2009, 27:431-441.

43. Thiery JP, Acloque H, Huang RY, Nieto MA: Epithelial-mesenchymal transitions in development and disease. Cell 2009, 139:871-890.

44. Peinado H, Olmeda D, Cano A: Snail, Zeb and bHLH factors in tumour progression: an alliance against the epithelial phenotype? Nat Rev Cancer 2007, 7:415-428.

45. Collighan RJ, Griffin M: Transglutaminase 2 cross-linking of matrix proteins: biological significance and medical applications. Amino Acids 2009, 36:659-670.

46. Kojima S, Nara K, Rifkin DB: Requirement for transglutaminase in the activation of latent transforming growth factor-beta in bovine endothelial cells. J Cell Biol 1993, 121:439-448.

47. Singer CF, Hudelist $G$, Walter I, Rueckliniger E, Czerwenka $\mathrm{K}$, Kubista $\mathrm{E}$, Huber AV: Tissue array-based expression of transglutaminase-2 in human breast and ovarian cancer. Clin Exp Metastasis 2006, 23:33-39.

48. Mehta K, Fok J, Miller FR, Koul D, Sahin AA: Prognostic significance of tissue transglutaminase in drug resistant and metastatic breast cancer. Clin Cancer Res 2004, 10:8068-8076.

49. Hwang JY, Mangala LS, Fok JY, Lin YG, Merritt WM, Spannuth WA, Nick AM, Fiterman DJ, Vivas-Mejia PE, Deavers MT, Coleman RL, Lopez-Berestein G, Mehta K, Sood AK: Clinical and biological significance of tissue transglutaminase in ovarian carcinoma. Cancer Res 2008, 68:5849-5858.

doi:10.1186/bcr3034

Cite this article as: Oh et al:: Transglutaminase 2 facilitates the distant hematogenous metastasis of breast cancer by modulating interleukin- 6 in cancer cells. Breast Cancer Research 2011 13:R96.

\section{Submit your next manuscript to BioMed Central and take full advantage of:}

- Convenient online submission

- Thorough peer review

- No space constraints or color figure charges

- Immediate publication on acceptance

- Inclusion in PubMed, CAS, Scopus and Google Scholar

- Research which is freely available for redistribution 